\title{
UNIMED LESTE FLUMINENSE: ALINHANDO OS CANAIS PARA CRESCER
}

\author{
Juliana Maffazioli Pires \\ jumpires@gmail.com \\ Universidade Federal do Rio de Janeiro - Rio de Janeiro, RJ / Brasil \\ Alice Souto de Vasconcelos Torres \\ alice.torres@gmail.com \\ Universidade Federal do Rio de Janeiro - Rio de Janeiro, RJ / Brasil \\ Victor Manoel Cunha de Almeida \\ valmeida@coppead.ufrj.br \\ Universidade Federal do Rio de Janeiro - Rio de Janeiro, RJ / Brasil
}

\begin{abstract}
Recebido em 10/05/2013
Aprovado em 17/05/2013

Disponibilizado em 01/12/2013

Avaliado pelo sistema double blind review

Revista Eletrônica de Administração

Editor: Luís Felipe Nascimento

ISSN 1413-2311 (versão on-line)

Editada pela Escola de Administração da Universidade Federal do Rio Grande do Sul.

Periodicidade: Quadrimestral

Sistema requerido: Adobe Acrobat Reader.
\end{abstract}

\section{RESUMO}

O caso de ensino Unimed Leste Fluminense apresenta uma situação decisória que deve ser enfrentada por Dilson Reis, diretor de mercado da organização. O caso descreve a trajetória da empresa desde a sua fundação e apresenta o momento em que o diretor, pressionado pela concorrência e pela grande regulação do setor, questiona como aumentar a sua base de clientes. No momento da decisão, o setor apresenta forte intensificação na competição, sendo a maior disputa pelos grandes clientes empresariais, tanto entre os operadores de planos de saúde quanto entre os corretores que vendiam esses planos. A preferência por clientes empresariais decorria principalmente das restrições impostas pela regulamentação da Agência Nacional de Saúde Suplementar, aplicáveis aos clientes pessoa física. A estrutura de canais da Unimed Leste Fluminense não era bem definida, já que seus canais de venda competiam pelo atendimento de clientes pessoa física e jurídica, não havendo uma gestão coordenada de lojas, vendedores próprios, concessionárias e corretores. Nesse contexto, os possíveis conflitos de canal desgastavam a operadora, que fazia de tudo para conquistar o cliente, mas tinha pouco poder de influência sobre os parceiros de canais. O caso proporciona uma oportunidade para a discussão sobre a necessidade de alinhamento de estrutura dos canais de marketing aos objetivos de crescimento da firma. Possibilita ainda uma reflexão sobre a natureza dos conflitos multicanal e as ações requeridas para o gerenciamento de canais. Trata-se de um caso real, elaborado a partir de entrevistas em profundidade com Benito Petraglia, Dilson Reis e Jair da Costa Jr., respectivamente diretor administrativo, diretor de mercado e gerente de mercado da Unimed Leste Fluminense. Para facilitar o processo de envolvimento dos alunos, o dilema do caso foi apresentado na perspectiva de Dilson Reis. Informações secundárias foram utilizadas para triangulação dos dados e para complementação da descrição do caso.

REAd | Porto Alegre - Edição 76 - N 3 - setembro/dezembro 2013 - p. 796-819 
Juliana Maffazioli Pires, Alice Souto de Vasconcelos Torres \& Victor Manoel Cunha de Almeida

Utilizaram-se ainda dados secundários para descrever o setor de saúde suplementar, mais especificamente o segmento de planos de saúde, de forma a oferecer ao aluno a possibilidade de contextualização do caso. Recomenda-se a discussão do caso nas disciplinas de canais de distribuição ou canais de marketing em cursos de pós-graduação lato ou stricto sensu, especialmente para programas cujo método supõe a aprendizagem centrada no participante. Espera-se que o aluno assuma papel ativo na preparação individual do caso, discussão em grupo e na sessão plenária.

Palavras-chave: Canais de Marketing; Canais de Distribuição; Conflito Multicanal; Setor de Saúde Suplementar; Caso de Ensino.

\title{
UNIMED LESTE FLUMINENSE: ALIGNING CHANNELS TO GROW
}

\begin{abstract}
The Unimed Leste Fluminense teaching case presents a decisive situation faced by Dilson Reis, the organization market director. The case describes the company's history since its foundation and highlights the moment in which the director, pressured by both competition and extensive regulations of the industry, wonders how to increase its customer base. At the time of the decision, the industry had greatly intensified competition, with the most intense disputes being for large corporate clients, including both among health insurance sales agents and among the brokers who sold these plans. The preference for corporate clients stemmed primarily from the restrictions imposed by the regulations of the National Agency for Supplementary Health (ANS), which apply only to individual customers. The structure of sales channels of the Unimed Leste Fluminense was not well defined, as they competed for both individual customers and corporate clients, without any form of coordination of management of the stores, sales representatives, dealers or brokers. The company was worried about the potential sales channels conflicts, since it was doing everything to win over customers, but had little influence over its sales partners. The case provides an opportunity for discussion on the need to align the marketing channels structure to the firm's growth objectives. It also allows for reflection on the nature of multi-channel conflicts and the actions required for their management. This is a real life case, drawn from interviews with Benito Petraglia, Dilson Reis and Jair da Costa Jr., managing director, director of marketing and market manager of the Unimed Leste Fluminense office respectively. To facilitate the process of student involvement, the dilemma of the case was presented from Dilson Reis' perspective. Secondary information was used for data triangulation and to enrich the case description. Secondary data was also used to describe the private health care sector, more specifically the segment of health insurance plans, to offer students the opportunity to contextualize the case. The discussion of the case in the disciplines of distribution and marketing channels in postgraduate courses is recommended, especially for programs whose method assumes a participant-centered learning approach. It is expected that the student takes an active role in the individual case preparation, group discussions and the plenary session.
\end{abstract}

Keywords: Marketing Channels; Distribution Channels; Multichannel Conflict; Supplementary Health Sector; Teaching Case. 


\section{INTRODUÇÃO}

Naquele fim de tarde de sexta-feira, depois de um dia cheio em seu consultório, Dilson Reis enfrentava o engarrafamento típico da Ponte Rio-Niterói para chegar à reunião convocada por Benito Petraglia na sede da Unimed Leste Fluminense em Niterói. Ali, parado no vão central há mais de 45 minutos, ele refletia sobre a boa perspectiva de crescimento para a cooperativa naquele ano. Havia muito investimento industrial na região de atuação da Unimed Leste Fluminense. Observando a bela vista da enseada de Botafogo, Dilson pensava na excelente oportunidade que se apresentava para ampliar a participação nesse mercado. Conhecia o potencial de sua equipe própria de vendas, no entanto ainda não tinha clareza sobre como integrar os diversos canais de vendas para suportar esse crescimento. Mais especificamente, ainda não sabia como tratar a relação da Unimed com os grandes corretores de seguros de saúde, que naquele momento constituíam o principal canal de venda para pessoas jurídicas. Dilson já estava atrasado. Quanto mais olhava para o relógio no painel do carro, mais rápido o tempo parecia avançar. Só não avançavam os carros e as ideias para a reunião com Petraglia.

\section{ANTECEDENTES}

A Unimed Leste Fluminense foi fundada em junho de 1971. Foi a primeira cooperativa do Estado do Rio de Janeiro e a quinta no Brasil, abrangendo as cidades de Niterói, São Gonçalo, Itaboraí, Maricá, Tanguá, Rio Bonito e Silva Jardim. Durante boa parte de sua história, a Unimed Leste Fluminense ocupou uma posição confortável em seu mercado. Sem concorrentes diretos e com uma marca consagrada, manteve sua liderança nas regiões em que atuava, sem grandes esforços para conquistar e manter clientes - sendo, na prática, procurada por estes.

O panorama começou a mudar rápida e drasticamente com a criação de uma agência reguladora vinculada ao Ministério de Saúde, Agência Nacional de Saúde Suplementar (ANS), e o surgimento de concorrência por parte de outras grandes operadoras de saúde. Estas, com a saturação do mercado na capital do estado, passaram a perceber a área geográfica de atuação da Unimed Leste Fluminense como potencial e promissor espaço para a expansão de seus negócios, especialmente após o surgimento de novos projetos de desenvolvimento industrial na região.

REAd | Porto Alegre - Edição 76 - N 3 - setembro/dezembro 2013 - p. 796-819 
Juliana Maffazioli Pires, Alice Souto de Vasconcelos Torres \& Victor Manoel Cunha de Almeida

No ano de 2002, a cooperativa esteve a um passo de sofrer uma Direção Fiscal intervenção direta da ANS diante da constatação de irregularidades econômico-financeiras e administrativas, como atrasos no pagamento de fornecedores, desequilíbrio atuarial e evasão excessiva de beneficiários. A Direção Fiscal é o passo anterior à liquidação da empresa, com a transferência de sua carteira de clientes para outra operadora, financeiramente saudável.

Para evitar tal desfecho, a diretoria, que acabara de ser empossada, apresentou à ANS um plano de recuperação, com um cronograma de execução e propostas concretas para um controle de custos mais eficiente, aumento da receita e ampliação da carteira de clientes. No balanço contábil de 2002 foi apurado um prejuízo superior a R\$ 7 milhões, montante compartilhado por todos os cooperados, em uma decisão inédita. Sobre o fato, Dilson Reis relatou: "Esse episódio traumático foi um divisor de águas na trajetória da cooperativa. Marcou o fim do amadorismo empresarial e o início de uma forte recuperação financeira”.

Após o período de crise, a cooperativa começou a se destacar, disputando espaço com as outras operadoras de saúde. A empresa acredita que esse resultado foi possível graças à reestruturação de todos os setores e à sinergia entre colaboradores e gestores no cumprimento de metas e objetivos estabelecidos pelo Conselho de Administração da Unimed Leste Fluminense. Conforme relatou Benito Petraglia, diretor administrativo da Unimed Leste Fluminense: "o crescimento foi reflexo do favorecimento de mercado, da experiência de gestão e de investimentos em tecnologia da informação, além de um rigoroso controle financeiro".

\section{SETOR DE SAÚDE SUPLEMENTAR}

O setor de saúde suplementar no Brasil é considerado a principal fonte de financiamento para hospitais, redes de laboratórios de medicina diagnóstica e profissionais de saúde. Os planos de saúde privados receberam destaque a partir da década de 1960, com o objetivo de garantir assistência médica alternativa e de melhor qualidade. O segmento de saúde suplementar privada tem registrado uma considerável taxa de crescimento, de modo que, nos últimos anos, o crescimento do número de vínculos de beneficiários tem superado a taxa de crescimento da população brasileira, resultando no aumento da taxa de cobertura.

No entanto, o setor de saúde suplementar pode ser dividido entre antes e depois da ANS. Antes de sua criação, não havia regras específicas para o setor, e as operadoras REAd | Porto Alegre - Edição 76 - N 3 - setembro/dezembro 2013 - p. 796-819 
Unimed Leste Fluminense: alinhando os canais para crescer

definiam livremente a cobertura assistencial, reajustavam os preços dos planos e determinavam as carências, ou seja, estabeleciam contratos segundo seus próprios padrões e interesses.

Quando a ANS foi criada, em 1998, havia cerca de 2.600 operadoras ativas, com registro, com ou sem beneficiários. Após dez anos, este número foi reduzido em mais de mil operadoras, o que mostra seu impacto no setor de saúde suplementar. A ação regulamentadora da ANS exigiu uma evolução do ponto de vista da gestão empresarial no setor. Seus principais poderes estão relacionados no Quadro 1 (ver Anexo 1).

\subsection{Segmento de Planos de Saúde}

Operadoras de Planos de Saúde são as empresas que operam no setor de saúde suplementar, oferecendo aos consumidores os planos de assistência à saúde. Com base nas informações recolhidas no setor, a ANS definiu oito modalidades de operadoras de serviços de saúde: administradoras, cooperativas médicas, cooperativas odontológicas, instituições filantrópicas, autogestões, que podem ser patrocinadas ou não patrocinadas, seguradoras especializadas em saúde, medicina de grupo e odontologia de grupo.

Um plano de saúde constitui uma forma específica de prestação de serviços de saúde pela iniciativa privada. É também chamado de contrato de plano de saúde, pelo qual o consumidor paga uma prestação em dinheiro e, caso precise de qualquer serviço, a empresa contratada deve prestá-lo por meio de sua rede credenciada, sem nenhum ônus financeiro para o consumidor.

Na avaliação de Benito Petraglia, nos últimos anos, as grandes operadoras estariam optando por desenvolver uma rede própria de hospitais, centros médicos e laboratórios, por considerarem que esta é a forma mais adequada e eficiente de oferecer serviços de saúde a todos os segmentos da população. Ainda de acordo com o diretor administrativo, os investimentos na criação, expansão, ou aquisição de instalações médicas e laboratoriais próprias permitem que as operadoras prestem serviços diretamente ao cliente, complementando os que a rede credenciada já disponibiliza.

Empresas de planos de saúde e grandes redes de hospitais têm anunciado significativos investimentos de recursos na saúde de Niterói. Os gastos registrados até o final de 2010 somavam mais de 100 milhões de reais para a construção de novos hospitais e para ampliar a

REAd | Porto Alegre - Edição 76 - N 3 - setembro/dezembro 2013 - p. 796-819 
Juliana Maffazioli Pires, Alice Souto de Vasconcelos Torres \& Victor Manoel Cunha de Almeida

capacidade em mais de 800 novos leitos. ${ }^{2}$ Segundo Valéria Patrocínio, coordenadora do departamento de mercado da Unimed, há uma preocupação em atender à demanda da cidade, que se expande rapidamente: "mais do que o crescimento de nossa carteira, pretendemos ser a operadora de saúde com maior qualidade de atendimento."

Outra tendência observada no setor é o foco maior nos planos coletivos, com algumas empresas - como SulAmérica e Bradesco Saúde - deixando de oferecer planos individuais, e outras, demonstrando desinteresse por esse tipo de contrato, instruindo corretores a não comercializarem ou pagando comissões mais baixas. Em entrevista a revista Isto é Dinheiro, ${ }^{3}$ o diretor da SulAmérica, Hélio Novaes, comentou que a decisão de parar de vender planos de saúde para pessoa física ocorre principalmente devido à incerteza no setor, causada pela interferência da ANS. Para Novaes, a Lei 9.656 encareceu o custo médio dos planos individuais e familiares, ao obrigá-los a darem cobertura para todos os procedimentos - como partos, tratamentos para AIDS, transplantes - mesmo que não fosse a vontade do cliente. Novaes defende que deveria haver livre escolha por parte do cliente, com transparência nos contratos:

\footnotetext{
As restrições não podem aparecer naquelas letrinhas miúdas. O cliente tem que saber o que levou para casa. Mas antes tinha também outra coisa esquisita. $\mathrm{O}$ sujeito não tinha uma cobertura, era ciente disso, mas procurava o Poder Judiciário. O que fazia o juiz? Mandava a seguradora atender. E ainda dizem que nós, das empresas de saúde, somos as piores pessoas do mundo.
}

Cabe ressaltar que nos contratos coletivos a ANS não atua em situações de reajustes de preço e cancelamento de contrato, por considerar que seria um acordo entre duas pessoas jurídicas, com suposta paridade de forças, não sendo, portanto, necessária a sua atuação. Com isso, o mercado observa um fenômeno conhecido como "falsa coletivização". Empresas como Samcil, Medial, SulAmérica e Bradesco Saúde permitem a contratação de planos de saúde coletivos por grupos formados a partir de cinco pessoas. O resumo das principais intervenções da ANS está apresentado no Quadro 2 (ver Anexo 2).

\section{UNIMED LESTE FLUMINENSE}

A Unimed Leste Fluminense oferece planos com cobertura regional, estadual ou nacional, que podem ser individuais e familiares ou corporativos. O termo cobertura é utilizado para especificar a abrangência geográfica onde o beneficiário poderá ser atendido.

REAd | Porto Alegre - Edição 76 - N 3 - setembro/dezembro 2013 - p. 796-819 
Unimed Leste Fluminense: alinhando os canais para crescer

No contexto da reestruturação organizacional e da mudança de postura promovida na Unimed Leste Fluminense, a área comercial da empresa merece atenção especial. Não somente em termos de estrutura, mas, principalmente, no que se refere à filosofia e à forma de atuação. Nas palavras de Dilson Reis, "a estratégia está centrada na tensão dos movimentos de mercado, na conscientização dos cooperados e na administração ágil e profissionalizada".

Ainda de acordo com Dilson Reis, o cenário mercadológico para os operadores de planos de saúde é extremamente instável, competitivo e as projeções indicam que ficará ainda mais difícil, não havendo dúvidas de que poucos poderão sobreviver às novas necessidades e desafios do setor. A venda desenfreada de planos de saúde, sem critérios, sem uma estratégia definida e sem parâmetros bem desenhados, tem sido uma das principais causas de insolvência e fechamento de inúmeras operadoras nos últimos anos.

Por esse motivo, o diretor de mercado relatou que a rotina da operadora se modificou para ouvir os cliente e suas opiniões. Essa postura se reflete numa maior aproximação com os clientes, em especial com os gestores de empresas, responsáveis pela negociação, contratação e renovação de contratos dos planos de saúde, e o estabelecimento de um diálogo constante.

O desafio de atuar em mercados competitivos e altamente regulados provou ser um excelente estímulo para a Unimed Leste Fluminense, que, em oito anos, passou de 59 mil para 170 mil clientes, dos quais $44 \%$ são individuais ou familiares (pessoa física) e $56 \%$ são corporativos (pessoa jurídica). O gráfico apresentado na Figura 1 (ver Anexo 3) demonstra a evolução do número de clientes da Unimed Leste Fluminense.

Dilson Reis lamenta o fato de não existirem metas formais de venda por região, por canal, ou por segmento de clientes. De acordo com o diretor de mercado, a empresa operava apenas com o desejo de aumentar o número acumulado de clientes para 180 mil no final de 2011.

\subsection{Planos Individuais e Familiares}

Costuma-se dizer entre os vendedores de planos de saúde que, para o cliente pessoa física, o plano Unimed "se vende sozinho". Mesmo com a tímida campanha de vendas da Unimed Leste Fluminense quando comparada à dos grandes operadores de planos de saúde, a Unimed ainda se mantém mais atrativa, pois investe em parcerias estratégicas, com hospitais e laboratórios. A Unimed acredita que esse seja o seu grande diferencial. Para Jair da Costa

REAd | Porto Alegre - Edição 76 - N 3 - setembro/dezembro 2013 - p. 796-819 
Juliana Maffazioli Pires, Alice Souto de Vasconcelos Torres \& Victor Manoel Cunha de Almeida

Junior, gerente de mercado, o plano para pessoa física se caracteriza por uma venda imediata, ou seja, o cliente que procura um plano de saúde fecha o contrato na hora e dificilmente posterga a decisão:

No caso do plano para pessoa física, tudo começa com uma indicação. Alguém sabe que você está procurando o plano de saúde, e te indica um vendedor. O cliente procura o vendedor e a venda acontece na hora. Ou é ali ou não vende e isso serve para qualquer plano, não só o da Unimed.

Em 2008, a Unimed lançou o "Unimed Fácil”. Um plano co-participativo voltado principalmente para a classe $\mathrm{C}$, que permite mensalidades de menor valor. Quando é necessária a utilização para exames e consultas, o usuário paga estes à parte, também com valores reduzidos e com a qualidade Unimed. Benito Petráglia afirma que investir no segmento de classe $\mathrm{C}$ é essencial para o crescimento das operadoras de plano de saúde, uma vez que acredita que o mercado de classes A e B já está saturado.

O nicho que está surgindo no mercado de plano de saúde é o da classe C, principalmente, pela estabilização da economia. Essas pessoas estão se inserindo no mercado consumidor e com isso acabam comprando um plano de saúde que é um objeto de desejo. No entanto, as operadoras precisam adequar o produto àquele poder aquisitivo, então, eles lançam produtos com uma mensalidade menor e também com uma cobertura menor. E o Unimed Fácil é um desses produtos.

O Unimed Fácil assumiu rapidamente a condição de produto principal na comercialização de planos individuais e familiares. Além disso, permitiu a retenção de clientes que não podiam pagar os valores dos planos sem co-participação, proporcionando, além do crescimento, uma maior fidelização da atual carteira de clientes.

A campanha de marketing do plano Unimed Fácil foi iniciada em agosto de 2008, sendo observada a comercialização dos 73 primeiros planos em novembro daquele ano. $\mathrm{Na}$ oportunidade, a representatividade foi de $7,42 \%$ do volume total de vendas. A partir daí, o produto vem superando as expectativas, tendo atingido em menos de um ano a marca de $51,9 \%$ das vendas de novos planos.

Em 2011, a Unimed possuía cinco tipos de planos destinados à pessoa física que se diferenciavam quanto à abrangência, oferecendo cobertura nacional ou exclusivamente na região da Unimed Leste Fluminense. Também se diferenciavam pelo tipo de acomodação hospitalar, em quarto particular ou enfermaria. Em cada tipo de plano, os preços podiam variar dependendo do perfil do cliente. 


\subsection{Planos Empresariais}

A Unimed também oferecia dois tipos de plano destinados à pessoa jurídica que se diferiam quanto ao número de funcionários da empresa: um plano para empresas com até 30 funcionários e outro para empresas com mais funcionários.

A venda para pessoa jurídica é feita principalmente através de corretores, que exercem grande influência no setor. As negociações de planos de saúde para esses clientes são mais longas e precisam ser trabalhadas tipicamente durante meses pelos corretores em parceria com a Unimed. Apesar de a Unimed estar oferecendo mais suporte aos corretores, ainda não é possível acompanhar essas oportunidades de vendas, já que não existe um monitoramento formal das ofertas para pessoas jurídicas.

De acordo com Dilson Reis, é comum que um cliente em potencial comece a negociação com um corretor, que se dedica intensamente junto ao departamento comercial da Unimed para oferecer uma boa proposta, entretanto, nada impede que o cliente realize o contrato com outro corretor. Para esses casos, a Unimed não pode interferir, pois não possui o vínculo com os corretores, da mesma forma que possui com as concessionárias e vendedores próprios. A única possibilidade que está ao alcance do departamento comercial é orientar os clientes a respeitarem o corretor que se esforçou pela venda, ou ainda alertar o vendedor que fez o primeiro contato sobre a "disputa" pelo seu cliente. Alguns vendedores preferem não se envolver com vendas para grandes grupos, porque sabem que a disputa por eles é "briga de cachorro grande".

Para minimizar problemas desse tipo, o corretor registra na Unimed Leste Fluminense a oportunidade de venda que ele está trabalhando. Mas, normalmente, isso não faz diferença para o cliente, e é ele quem decide com que corretor quer fechar o negócio, por mais injusto que possa parecer. Quando isso ocorre, a operadora se vê de mãos atadas, pois essa é a prática do mercado.

Para a Unimed Leste Fluminense, fechar contratos com clientes do tipo pessoa jurídica é considerado muito estratégico, pois é uma maneira de crescer rapidamente em quantidade de usuários e em faturamento, além de estreitar o relacionamento com os corretores. Em 2010, os dois principais clientes corporativos da Unimed foram o Estaleiro Mauá e a Ampla.

\subsection{Canais de Vendas}

REAd | Porto Alegre - Edição 76 - N 3 - setembro/dezembro 2013 - p. $796-819$ 

Almeida

No início de 2011, a Unimed Leste Fluminense contava com 14 vendedores próprios; seis lojas concessionárias, que não eram exclusivas à Unimed - cada uma com 15 vendedores em média -; e corretores, que são vendedores autônomos. Além disso, possuía uma loja própria no shopping Itaipu Multicenter, localizado na região oceânica de Niterói, que servia para motivar o vendedor, conforme relatou Jair da Costa Junior:

Nós disponibilizamos a loja em um bom ponto de venda, onde podemos desenvolver ações que atraem o cliente para entrar e comprar um plano Unimed. Dessa forma o vendedor que está no plantão da loja fica mais motivado.

No site da empresa, as informações gerais dos planos são disponibilizadas de maneira clara para clientes e não clientes. Existe uma seção chamada "Quero ser cliente", que possibilita o preenchimento de um formulário pelo interessado. Desse modo, é gerada uma “indicação" que segue para um vendedor interno, de acordo com a ordem do plantão.

Não havia restrição de venda de planos por canal, dessa forma, todos os canais podiam vender tanto para pessoa física quanto para pessoa jurídica. Nesse contexto, a Unimed vinha buscando, ao longo dos anos, estabelecer uma maior proximidade com o consumidor, por meio da ampliação dos seus canais de venda e de uma estratégia de distribuição, focada em novas oportunidades de negócio. Jair da Costa Jr. explica a principal a diferença entre eles:

A diferença fundamental entre o vendedor de uma concessionária e o corretor é o vínculo com a Unimed. Um corretor pode ir diretamente à Unimed Leste Fluminense para negociar um contrato, enquanto a concessionária tem que vender planos com certa regularidade para manter a sua concessão. Para ser um corretor é necessário concluir cursos específicos na Escola Nacional de Seguros, a Funenseg, e ter os registros correspondentes, tanto na Superintendência Nacional de Seguros, Susep, como no Sindicato de Corretores de Seguros, o Sincor.

A cada novo produto, nova regra de negócio ou nova flexibilização do plano, torna-se necessário o treinamento de toda a força de vendas. Por exemplo, com o novo sistema de cadastramento de vendas online, foi necessária a realização de diversas sessões de treinamento que ficam sob responsabilidade das corretoras e das concessionárias. Jair da Costa Jr. sabe que é importante manter uma campanha de vendas junto às concessionárias, para que a Unimed Leste Fluminense seja lembrada pelos vendedores:

Não basta o cliente querer comprar, o vendedor tem que colocar o seu produto pra vender, e nós conseguimos isso através da campanha de vendas, mesmo sendo muito tímida comparada com o mercado. Operadoras como a Amil, Sulamérica fazem campanhas muito mais agressivas, sorteando automóveis, viagens internacionais, entre outros prêmios para vendedores e

REAd | Porto Alegre - Edição 76 - N 3 - setembro/dezembro 2013 - p. 796-819 
Unimed Leste Fluminense: alinhando os canais para crescer

corretores. Então você precisa estar junto do seu vendedor, se não ele simplesmente te deixa de lado. Aí, mesmo que o cliente solicite o plano da Unimed, o vendedor vai falar mal da Unimed e vai tentar vender Amil, porque lá ele tem uma campanha que é premiada pela venda.

A Unimed Leste Fluminense distribui uma pequena verba de campanha entre as concessionárias, além de distribuir material promocional e brindes, para que cada uma monte a sua própria campanha. Mas, ainda assim, é necessário compensar a desvantagem em relação às outras operadoras. A empresa acredita que a compensação se dá através de sua rede diferenciada, do forte nome no mercado, do atendimento ao vendedor, e de algumas parcerias que fazem com que o cliente solicite o plano da Unimed, ficando mais difícil para o vendedor "empurrar" outro plano. A campanha é uma maneira dos vendedores se sentirem prestigiados pela operadora.

\subsection{Política de Preços}

Os preços dos planos individuais são tabelados para todos os canais. Condições especiais podem ser oferecidas para grupos, não necessariamente empresariais, como, por exemplo, professores de um determinado município. Nesse caso, um corretor ou uma concessionária que tenha acesso ao nicho pode negociar com a Unimed Leste Fluminense um preço diferenciado. O preço final vai ser definido em função da quantidade de pessoas, da atividade desempenhada pelo grupo, da localização, e, principalmente, da comissão que o corretor está disposto a receber por aquele contrato, pois o vendedor pode reduzir sua comissão para efetivar um negócio.

Quanto maior o grupo, sobretudo os empresariais, maior o interesse da operadora em fechar o negócio o mais rápido possível. Mas as negociações costumam demorar meses. E nesse tempo, as características do grupo podem mudar, alterando as condições do contrato que está sendo negociado, além de aumentar o interesse dos corretores em garantir aquela oportunidade. Sobre o assunto, Dilson Reis relata:

É possível que uma empresa procure dois ou mais corretores para negociar melhores condições de preço. Um dos corretores pode batalhar a venda por meses e para dar um diferencial para o cliente ainda reduz sua comissão para alcançar um valor mais atrativo. No entanto, a empresa pode mandar a proposta recebida para outro corretor, que vem até a Unimed e quer a mesma condição, mas sem a redução de sua comissão. E nós não podemos interferir. 
Juliana Maffazioli Pires, Alice Souto de Vasconcelos Torres \& Victor Manoel Cunha de Almeida

\section{PRÓXIMOS PASSOS}

Chegando ao prédio da Unimed Leste Fluminense, Dilson Reis sabia que a reunião com a diretoria não seria fácil. Todos o esperavam para a apresentação de um plano de expansão para a cooperativa naquele ano, mas ele ainda não estava seguro sobre o que havia preparado. Ele sabia que a Unimed não tinha controle sobre os corretores de plano de saúde, no entanto, sua equipe própria de vendas não tinha força para alcançar o mercado de pessoa jurídica, ainda dominado pelos corretores. Além disso, a Unimed tinha que buscar formas de se tornar cada vez mais atrativa ao consumidor pessoa física, a ponto de ele requisitar seu plano, sem considerar os outros, já que os demais planos investiam em promoções e recompensas às concessionárias de venda.

Dilson Reis tinha razões para questionar a política de aquisição de novos clientes. A cooperativa necessitava avaliar os riscos da parceria com os grandes corretores de seguros de saúde, que dificultavam o monitoramento das negociações e das ofertas de serviço para empresas. E precisava rever como estava sendo feita a venda de planos para pessoa física pelas concessionárias. Tudo isso sinalizava a necessidade de uma mudança no relacionamento da Unimed com seus canais de venda.

Às 19 horas em ponto, Benito Petraglia abriu a reunião com a notícia de que em janeiro de 2011 a Unimed Leste Fluminense havia ultrapassado a marca de 170 mil clientes, o que demonstrava que a cooperativa estava a caminho dos 180 mil filiados no final de 2011. De acordo com a avaliação do diretor administrativo o futuro seria ainda mais promissor para a cooperativa, já que em breve seriam inauguradas novas unidades próprias de atendimento médico para garantir maior qualidade aos seus clientes, além de proporcionar ao médico cooperado um ambiente com elevado padrão tecnológico. Em seguida, Petraglia passou a palavra a Dilson Reis.

\footnotetext{
${ }^{1}$ ANS. Site da ANS. Disponível em: www.ans.gov.br. Acesso em: 7 de julho de 2010.

${ }^{2}$ SCHIMITT, G. L. Saúde privada niteroiense terá 100 milhões em investimento. Especial Niterói 435 anos, 2008. p. 40-41.

${ }^{3}$ ATTUCH, L. Vender plano de saúde ficou inviável. Revista Isto é Dinheiro. mar. 2010. Disponível em:

<http://www.istoedinheiro.com.br/noticias/12202_vender+plano+de+saude+ficou+inviavel >. Acesso em: 1 de julho de 2010.
} 
Unimed Leste Fluminense: alinhando os canais para crescer

\section{ANEXO 1}

Quadro 1 - Poderes da ANS

Estabelecer disposições contratuais a serem adotadas pelas operadoras de planos de saúde;

Estabelecer critérios para credenciamento e descredenciamento de operadoras de planos de saúde;

Estabelecer padrões de qualidade e cobertura das operadoras de planos de saúde;

Regulamentar condições pré-existentes;

Autorizar aumentos e ajustes de preços para as operadoras de planos de saúde suplementar;

Estabelecer padrões a respeito de dados econômicos e financeiros a serem apresentados pelas operadoras de planos de saúde para solicitar aumentos e ajustes de preço;

Autorizar o registro e o funcionamento de operadoras de planos de saúde e, mediante sua autorização prévia, autorizar cisões, incorporações, fusões, mudanças de controle e alienação de carteiras de beneficiários;

Supervisionar o cumprimento das normas por parte das operadoras de planos de saúde e/ou impor penalidades;

Liquidar operadoras de planos de saúde que tiverem sua autorização de funcionamento revogada.

Fonte: Adaptado do site da ANS - www.ans.gov.br 
Juliana Maffazioli Pires, Alice Souto de Vasconcelos Torres \& Victor Manoel Cunha de Almeida

ANEXO 2

Quadro 2 - Principais intervenções da ANS

\begin{tabular}{|c|c|c|}
\hline & $\begin{array}{l}\text { Planos } \\
\text { individuais/familiares }\end{array}$ & Planos coletivos \\
\hline Possibilidade de contratar & $\begin{array}{l}\text { Qualquer pessoa física pode } \\
\text { contratar }\end{array}$ & $\begin{array}{l}\text { Só é possível contratar com a intermediação de } \\
\text { pessoa jurídica (empresa, associação ou } \\
\text { sindicato) }\end{array}$ \\
\hline Preços iniciais & $\begin{array}{l}\text { Geralmente são mais caros } \\
\text { que os coletivos da mesma } \\
\text { operadora e de cobertura } \\
\text { equivalente }\end{array}$ & $\begin{array}{l}\text { Geralmente são mais baratos que os individuais } \\
\text { e familiares da mesma operadora e de cobertura } \\
\text { equivalente }\end{array}$ \\
\hline Reajustes & $\begin{array}{l}\text { Regulados e limitados pela } \\
\text { ANS }\end{array}$ & $\begin{array}{l}\text { Não são regulados pela ANS, geralmente são } \\
\text { maiores do que os impostos aos contratos } \\
\text { individuais/familiares }\end{array}$ \\
\hline Rescisão contratual & $\begin{array}{l}\text { ANS regula a questão e } \\
\text { veda rescisão unilateral pela } \\
\text { operadora }\end{array}$ & $\begin{array}{l}\text { ANS não regula e é prática corrente a rescisão } \\
\text { unilateral pelas operadoras }\end{array}$ \\
\hline Permanência no plano & Tempo indefinido & $\begin{array}{l}\text { Há a possibilidade de contrato e, em caso de } \\
\text { contrato coletivo empresarial, existem restrições } \\
\text { ligadas ao desligamento da empresa (demissão } \\
\text { ou aposentadoria) }\end{array}$ \\
\hline
\end{tabular}

Fonte: Adaptado do site da ANS - www.ans.gov.br 
Unimed Leste Fluminense: alinhando os canais para crescer

ANEXO 3

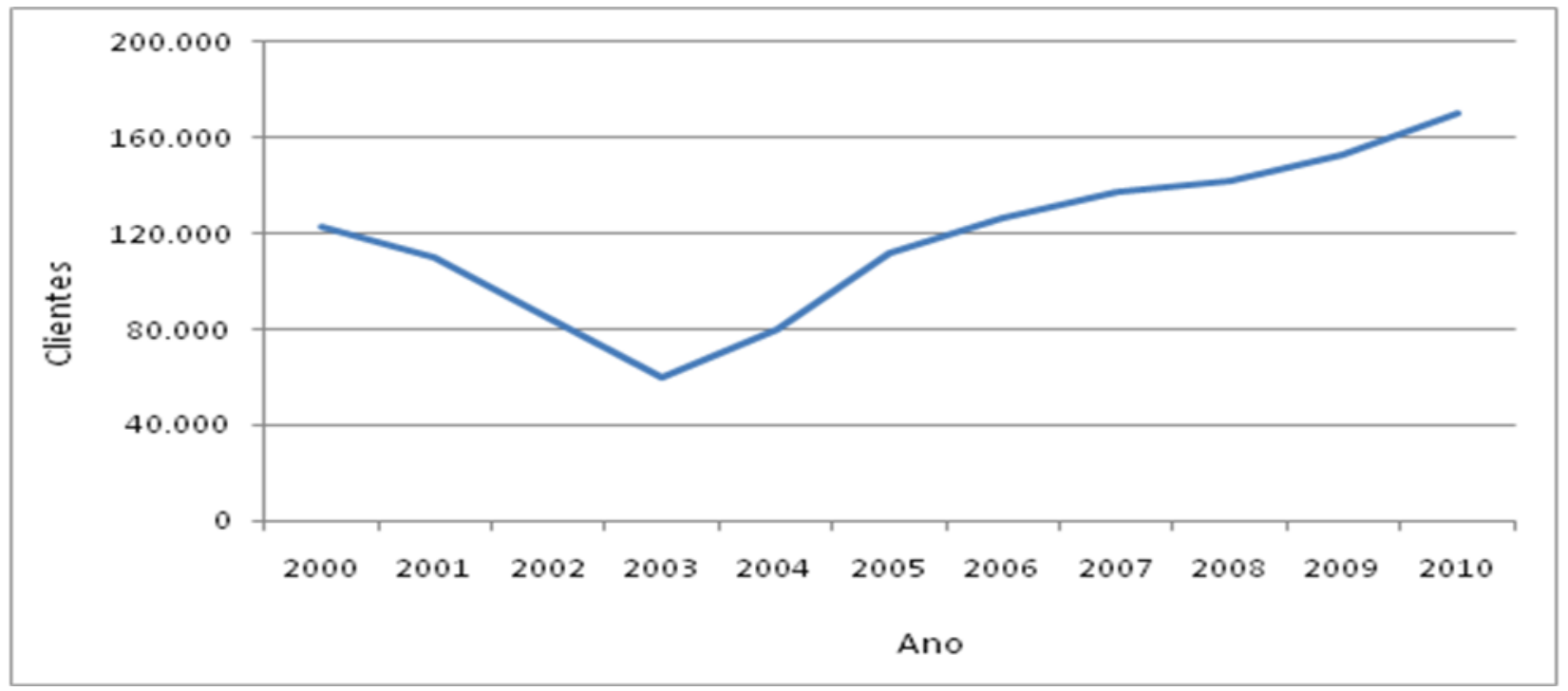

Figura 1 - Evolução do número de clientes da Unimed Leste Fluminense Fonte: Autoria própria. 
Juliana Maffazioli Pires, Alice Souto de Vasconcelos Torres \& Victor Manoel Cunha de Almeida

\section{NOTAS DE ENSINO}

\section{SINOPSE}

O caso Unimed Leste Fluminense descreve a trajetória da empresa desde a sua fundação e apresenta o momento em que o diretor, pressionado pela competição e pela grande regulação do setor, questiona como aumentar a sua base de clientes. No momento da decisão, o setor apresenta forte intensificação na competição, sendo que a maior disputa se dava pelos grandes clientes empresariais, tanto entre os operadores de planos de saúde quanto entre os corretores que vendiam esses planos. A preferência por clientes empresariais decorria principalmente das restrições impostas pela regulamentação da Agência Nacional de Saúde Suplementar, aplicáveis aos clientes pessoa física. A estrutura de canais da Unimed Leste Fluminense não era bem definida, já que seus canais de venda de planos de saúde competiam pelo atendimento de clientes pessoa física e jurídica, não havendo uma gestão coordenada de lojas, vendedores próprios, concessionárias e corretores. Nesse contexto, os conflitos de canal desgastavam a operadora, que fazia de tudo para conquistar o cliente, mas tinha pouco poder de influência sobre os parceiros de canais.

\section{OBJETIVOS DE ENSINO / APRENDIZAGEM}

Este caso foi desenvolvido para proporcionar uma discussão sobre os efeitos resultantes do desenho e alinhamento da estrutura de canais de distribuição. O caso apresenta uma situação de conflito multicanal, possibilitando que os alunos analisem a estrutura de canais e discutam alternativas de gerenciamento para lidar com a situação descrita.

Este caso foi idealizado para possibilitar a aprendizagem através do processo indutivo. Nessa circunstância, leituras prévias não seriam obrigatórias. Se o professor preferir, o caso pode ser acompanhado de leituras que familiarizem o aluno com os conceitos relacionados a gerenciamento de canais, mais especificamente o tópico de conflitos de canal (VINHAS; ANDERSON, 2005; SHARMA; MEHROTA, 2007), bem como os conceitos relacionados a processos comportamentais nos canais de marketing (ROSENBLOOM, 2002).

\section{PROTAGONISTA}

REAd | Porto Alegre - Edição 76 - N 3 - setembro/dezembro 2013 - p. 796-819 
O dilema do caso foi apresentado na perspectiva de Dilson Reis, diretor de mercado da Unimed Leste Fluminense. É o executivo responsável pelos canais de vendas da organização.

\section{FONTE DE INFORMAÇÕES}

Fontes primárias e secundárias foram utilizadas para a elaboração do caso. As fontes primárias foram coletadas através de entrevistas em profundidade realizadas com Benito Petraglia, diretor administrativo da Unimed Leste Fluminense, Dilson Reis, diretor de mercado e Jair da Costa Jr., gerente de mercado. As fontes secundárias foram diversas, como o site da Agência de Saúde Suplementar, o site da Unimed Leste Fluminense e entrevistas publicadas de diretores de outros planos de saúde em que abordavam a problemática do caso. As informações secundárias foram utilizadas para triangular as informações primárias, além de fornecer um contexto ao caso.

\section{ABERTURA DO CASO EM PLENÁRIO}

O caso Unimed coloca em evidência a decisão que deve ser tomada por Dilson Reis, diretor de mercado da Unimed Leste Fluminense, em relação à estrutura de canais de venda de planos de saúde da empresa. A importância da decisão sobre a estratégia de canal da Unimed é grande, pois a competição no setor é crescente e torna-se cada vez mais acirrada a disputa por clientes, tanto entre os operadores de planos de saúde quanto entre os corretores que vendem esses planos. Dessa forma, uma boa questão para a abertura da discussão em plenário poderia ser: "Como está organizado o mercado de planos de saúde e como a Unimed Leste Fluminense está inserida nesse mercado?" Assim, os alunos poderiam se colocar no lugar de diretores da empresa para refletir sobre os questionamentos de Dilson Reis em relação a dois aspectos: a) crescente competição no mercado de planos de saúde, principalmente após a criação da ANS, em 2000 - ambiente do caso; e b) estratégia atual da empresa, considerando as forças atuantes no canal de vendas - problema da empresa.

\subsection{Ambiente do caso}

Para dar início à contextualização da discussão do caso, o professor pode propor a seguinte pergunta: “Como a ANS alterou o segmento de planos de saúde no Brasil?"

REAd | Porto Alegre - Edição 76 - N 3 - setembro/dezembro 2013 - p. 796-819 
Juliana Maffazioli Pires, Alice Souto de Vasconcelos Torres \& Victor Manoel Cunha de Almeida

O segmento de saúde suplementar privada tem registrado uma considerável taxa de crescimento no Brasil. Especificamente na cidade de Niterói e região, esse aumento deveu-se ao crescimento da cidade, que apresentava, em 2011, grandes oportunidades de investimento para as operadoras de planos de saúde. No entanto, isso aumentou a concorrência na área de atuação da Unimed Leste Fluminense, pois novas empresas começaram a focar essa região. Um bom ponto de partida para a análise do ambiente, portanto, seria o questionamento sobre o que aconteceu no mercado logo após a criação da ANS. É interessante notar que as exigências do mercado aumentaram, com reflexo na redução do número de competidores no mercado, já que somente empresas fortes e estruturadas conseguiram se sustentar após a regulamentação. Como consequência, a rivalidade da concorrência tornou-se ainda maior. Conforme é relatado no caso, antes da criação da ANS as operadoras definiam livremente a cobertura assistencial e questões contratuais, conforme seus próprios interesses. Tal regulação fez com que o número de operadoras passasse de 2.600 para pouco mais de mil, em dez anos.

\subsection{Problema da Empresa}

Estabelecido um claro entendimento sobre o ambiente do caso, o professor pode estimular a discussão sobre o problema da empresa através do seguinte questionamento: "Como a Unimed poderia aumentar a sua influência no canal de marketing?"

A estratégia multicanal utilizada pela Unimed tem como objetivo principal aumentar o potencial de vendas da empresa, ao mesmo tempo em que amplia a capilaridade da distribuição de planos de saúde. Contudo, essa estratégia apresenta a dificuldade de coordenação dos diversos distribuidores de planos de saúde, por parte da cooperativa. Os canais são os mesmos para clientes pessoa física ou pessoa jurídica e como não existem metas claras para cada um dos canais de distribuição, fica claro que essa estrutura pode favorecer o surgimento de conflito multicanal. Mais especificamente, conflitos relacionados aos corretores independentes. Nesses casos, a Unimed não mantém uma relação de poder pleno sobre o canal, já que esses vendedores de planos de saúde são independentes e vendem diversos outros planos, além da Unimed.

Para Rangan e Bell (2006), o poder em um canal de distribuição é exercido de maneira sutil, através de ações que têm o objetivo de proteger e desenvolver o negócio e acabam influenciando os demais parceiros do canal. Assim, quanto maior o poder de um fornecedor 
Unimed Leste Fluminense: alinhando os canais para crescer

ou de um intermediário, maior será a sua influência em toda a cadeia de valor, sem necessariamente eliminar ou reduzir a participação dos membros do canal em questão. Os autores explicam que o poder do fornecedor normalmente está associado à originalidade de um produto, de uma tecnologia ou de uma marca. Já os intermediários podem exercer poder pelo conhecimento do mercado, incluindo o acesso e a capacidade de agrupar consumidores com diferentes interesses.

$\mathrm{Na}$ descrição do caso, percebe-se um conflito entre a Unimed e os corretores, principalmente em negociações com pessoas jurídicas. Fica clara a disputa pelo poder de produto e pelo poder de mercado. Assim, a alocação de lucros na cadeia de valor do canal pode ficar prejudicada, como, por exemplo, quando um corretor faz de tudo para fechar um contrato com uma grande empresa, reduzindo sua própria comissão para oferecer um preço mais competitivo, e a empresa acaba fechando negócio com outro corretor, pelo mesmo preço, sendo que o novo corretor não aceita que sua comissão seja reduzida. Conforme é observado no caso, a empresa não se sente no direito de interferir quando isso ocorre.

A Unimed sabe que precisa dos corretores para a sobrevivência do seu negócio, mas deve administrar o canal de distribuição de modo que exerça maior influência na venda dos planos de saúde. Apesar da precificação dos produtos ter um papel importante na cadeia de valor, Rangan e Bell (2006) alertam que os fornecedores não devem tentar impor uma política de margem uniforme para os intermediários, dando liberdade estratégica a eles. No entanto, quando os intermediários reduzem drasticamente suas margens, todo o canal é prejudicado pela redução de preços e margens para todos os parceiros. No caso da Unimed, os corretores estão exercendo uma grande força no canal. Nessas situações, Rangan e Bell (2006) sugerem que a parte que está sendo prejudicada deve buscar alternativas, para calibrar o poder do canal. Ou seja, a Unimed deve buscar alternativas para estruturar e aperfeiçoar o uso de seus intermediários. A Figura 1 ilustra o modelo proposto pelos autores. 
Juliana Maffazioli Pires, Alice Souto de Vasconcelos Torres \& Victor Manoel Cunha de Almeida

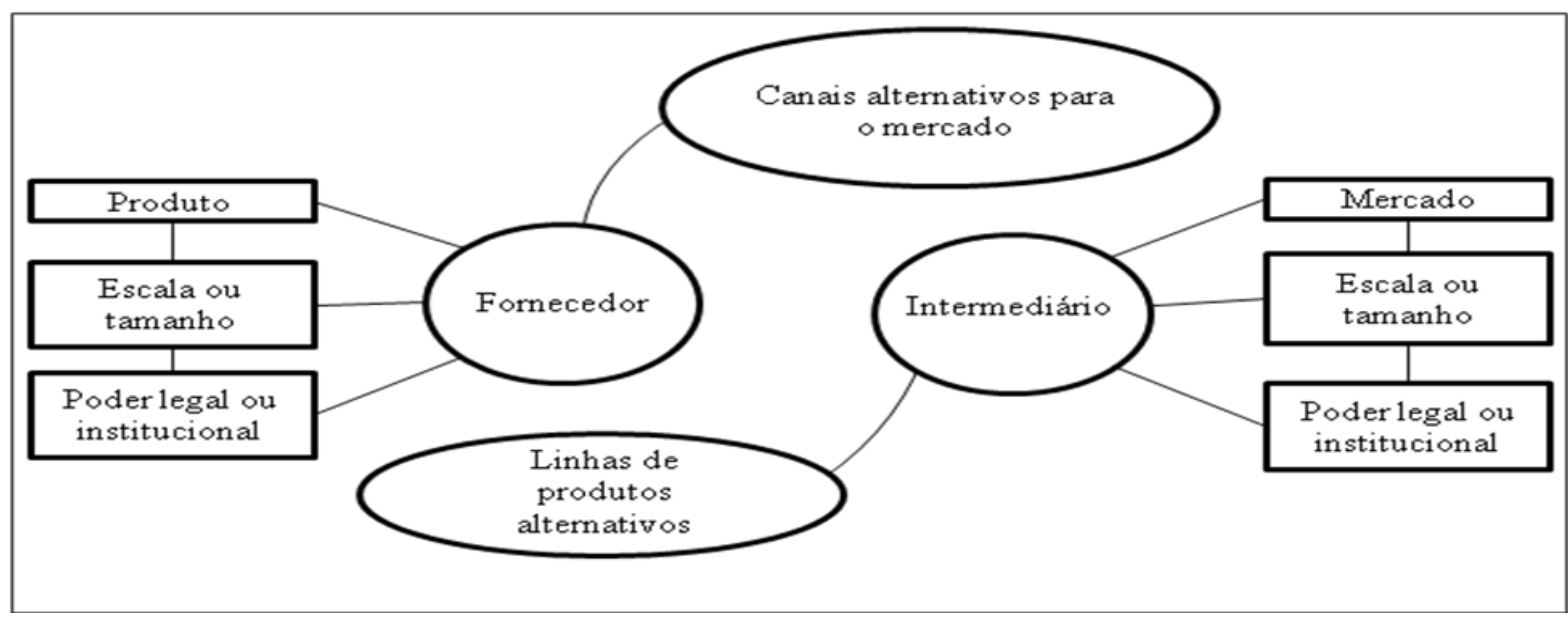

Figura 1 - Calibragem do poder do canal

Fonte: Adaptado de Rangan e Bell, 2006, p.107.

\section{QUESTÕES PARA DISCUSSÃO}

Como está estruturado o sistema de canais de venda da Unimed Leste Fluminense?

Que tipo de conflito de canal pode ocorrer em função da estratégia adotada pela Unimed Leste Fluminense?

Que segmento de clientes (pessoas físicas ou jurídicas) a Unimed deveria priorizar para suportar as metas de crescimento?

Como os canais de marketing podem ser reestruturados para mitigar os conflitos e suportar as metas de crescimento?

\section{ANÁLISE DAS QUESTÕES DO CASO}

\subsection{Como está estruturado o sistema de canais de venda da Unimed Leste Fluminense?}

Esta questão permite avaliar a atual estrutura de canal da Unimed mediante o desenho do diagrama do path-to-market da Unimed. Inicialmente, o aluno deve identificar a principal segmentação de clientes, entre clientes pessoa física e pessoa jurídica. Em seguida, deve refletir sobre como é realizada a venda de planos de saúde por meio dos diversos canais de distribuição da cooperativa. É importante que o aluno identifique, durante a preparação individual do caso, que existem quatro principais canais de venda dos planos Unimed: loja física, vendedores próprios, concessionárias e corretores. Assim, o path-to-market da Unimed Leste Fluminense pode ser representado pelo esquema ilustrado na Figura 2:

REAd | Porto Alegre - Edição 76 - N 3 - setembro/dezembro 2013 - p. 796-819 
Unimed Leste Fluminense: alinhando os canais para crescer

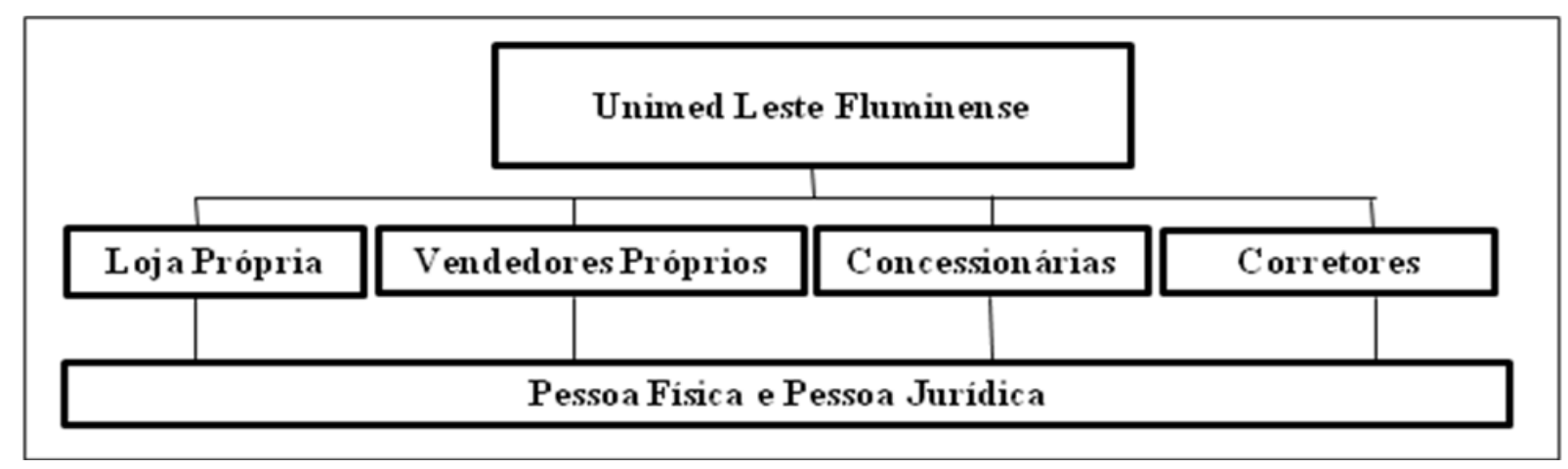

Figura 2 - Path-to-market da Unimed Leste Fluminense Fonte: Autoria própria.

O path-to-market ilustra o uso de canais simultâneos, que ocorre quando o fornecedor usa canais próprios, verticalmente integrados, e terceiros para cobrir uma mesma área geográfica e uma mesma linha de produtos (VINHAS; ANDERSON, 2005).

\subsection{Que tipo de conflito de canal pode ocorrer em função da estratégia adotada pela Unimed Leste Fluminense?}

O path-to-market demonstra que os canais são os mesmos para clientes pessoa física ou pessoa jurídica e como não existem metas claras para cada um dos canais de distribuição, fica claro que essa estrutura pode favorecer o surgimento de conflito multicanal. Como descrito no caso, não havia nenhuma restrição de venda de planos por canal, pois a Unimed buscava ampliar seus canais de venda para alcançar o maior número de clientes, caracterizando uma política de distribuição intensiva (ROSEMBLOOM, 2002).

O conflito multicanal ainda pode ser mais grave quando os vendedores independentes podem ter motivos para suspeitar que o fornecedor favorece seus empregados, enquanto os empregados se questionam se a gerência vai continuar com a integração vertical do canal uma vez que sustenta distribuidores independentes (VINHAS; ANDERSON, 2005).

Dentre as vendas para clientes pessoa jurídica, a maioria é feita por meio de corretores, que não possuem vínculo direto com a Unimed Leste Fluminense. No entanto, a Unimed valoriza os clientes corporativos por representarem uma maneira de crescer rapidamente em número de usuários. Esse conflito também pode ser observado nos casos de clientes corporativos free riders, que buscam informações e propostas com um membro do canal, mas fecham o pedido com outro. O caso descreve essa situação como algo comum, quando um 
Juliana Maffazioli Pires, Alice Souto de Vasconcelos Torres \& Victor Manoel Cunha de Almeida

corretor se dedica intensamente junto ao departamento comercial da Unimed para oferecer uma boa proposta a um cliente em potencial, mas o cliente opta por realizar o contrato com outro corretor. Como não existe vínculo entre a Unimed e os corretores, a cooperativa não pode interferir.

\subsection{Que segmento de clientes (pessoas físicas ou jurídicas) a Unimed deveria priorizar para suportar as metas de crescimento?}

Naturalmente, essa terceira questão não tem o propósito de buscar um consenso sobre qual seria o melhor segmento de clientes para a Unimed. O objetivo da questão é desenvolver uma discussão sobre as vantagens e desvantagens de cada uma das alternativas. Ao final dessa etapa da discussão, espera-se que os alunos tenham percebido a importância de manter os dois segmentos (pessoas físicas e jurídicas). O Quadro 1 sintetiza as principais vantagens e desvantagens de cada segmento de cliente.

Quadro 1 - Análise dos segmentos de clientes

\begin{tabular}{|ccc|c|}
\hline & Vantagens & Desvantagens \\
\hline $\begin{array}{c}\text { Pessoa } \\
\text { Física }\end{array}$ & $\begin{array}{c}\text { Diferenciar-se da tendência do mercado; Produto } \\
\text { lhe proporciona maior poder no canal para esse } \\
\text { cliente; Cobertura completa, garantida pela } \\
\text { regulamentação da ANS; Produto estabelecido } \\
\text { para a Classe C (Unimed Fácil). }\end{array}$ & $\begin{array}{c}\text { Muitos contratos são necessários para o crescimento de } \\
\text { sua base de clientes; Mensalidades fixas /mais caras, pela } \\
\text { inclusão de serviços que nem sempre são necessários; } \\
\text { Exigência de investimento de campanhas de venda com } \\
\text { as concessionárias; Necessidade de ampliar o número de } \\
\text { lojas próprias na área de atuação. }\end{array}$ \\
$\begin{array}{c}\text { Pessoa } \\
\text { Jurídica }\end{array}$ & $\begin{array}{c}\text { Expansão rápida do número de clientes com } \\
\text { apenas um contrato; Cobertura customizada; } \\
\text { Mensalidades negociáveis de acordo com o } \\
\text { número de usuários associados a pessoa jurídica. }\end{array}$ & $\begin{array}{c}\text { A contrapartida também é verdadeira, no encerramento } \\
\text { de um contrato perdem-se muitos clientes; Não possui } \\
\text { domínio na venda sobre esse segmento; Contrato não } \\
\text { regulamentado; Possibilidade de mudança do contrato a } \\
\text { qualquer momento por parte da operadora (ANS). }\end{array}$ \\
\hline
\end{tabular}

Fonte: Autoria própria.

\subsection{Como os canais de marketing podem ser reestruturados para mitigar os conflitos?}

Uma fonte importante de conflito provém da similaridade de domínio entre os canais (COUGHLAN, 2002; WEBB; HOGAN, 2002). No caso da Unimed Leste Fluminense, essa fonte de conflito pode ser observada a partir da análise do path-to-market.

Vinhas e Anderson (2005) destacam três abordagens eficazes para prevenir o conflito entre os canais: diferenciar as ofertas, criar regras e compensar os canais. Essas medidas 
Unimed Leste Fluminense: alinhando os canais para crescer

poderiam ser utilizadas pela Unimed para minimizar os conflitos de canal.

Uma sugestão para mitigar o conflito entre canais seria determinar que produtos serão vendidos ou priorizados em cada canal. A Unimed, por exemplo, poderia oferecer o Unimed Fácil apenas através da loja física e de vendedores próprios. Assim, caso um cliente com o perfil para esse plano procurasse outro canal, ele deveria ser encaminhado diretamente para a Unimed e receberia uma atenção especial para suas necessidades. Os demais planos também poderiam ser oferecidos pelos vendedores próprios, mas o foco para eles deveria ser o produto mais rentável para a empresa.

Quanto aos clientes corporativos, a Unimed poderia estabelecer uma parceria mais bem definida com os corretores independentes, criando uma comunicação específica e oferecendo serviços que atendam à demanda desses vendedores, como, por exemplo, uma linha direta para auxiliar na negociação. Isso poderia ser valorizado pelo corretor, que passaria a indicar mais a Unimed para as empresas. Desse modo, a cooperativa seria mais competitiva nesse segmento estratégico.

Por fim, as concessionárias poderiam se responsabilizar pelos planos individuais mais completos e planos coletivos não corporativos. Adicionalmente, a Unimed poderia alocar áreas comerciais (regiões geográficas) distintas aos principais parceiros de canal. Definida a mudança, seria necessário repensar o modelo de compensação dos canais.

Neste ponto da discussão, o professor poderia sugerir o redesenho do path-to-market para incorporar as alternativas discutidas na sessão plenária.

\section{CONSIDERAÇÕES FINAIS}

Como é típico dos casos de ensino, o da Unimed não admite uma única resposta. Os alunos, portanto, não devem ficar com a sensação de que se estivessem no lugar de Dilson Reis deveriam fazer isso ou aquilo para garantir o crescimento da cooperativa. Um encerramento apropriado para a discussão do caso poderia acontecer na forma da proposição de uma questão aberta sobre as possíveis reações da concorrência. Uma vez que esse setor vivia um acirramento da competição, poder-se-ia esperar uma resposta imediata dos principais competidores. O que faria a concorrência em resposta às mudanças no canal de vendas da Unimed?

REAd | Porto Alegre - Edição 76 - N 3 - setembro/dezembro 2013 - p. $796-819$ 
Juliana Maffazioli Pires, Alice Souto de Vasconcelos Torres \& Victor Manoel Cunha de Almeida

\section{REFERÊNCIAS}

COUGHLAN, A. T.; ANDERSON, E.; EL-ANSARY, A. I. Canais de Marketing e Distribuição. Porto Alegre: Bookman, 2002.

RANGAN, V. K.; BELL, M. Transforming Your Go-To-Market Strategy. Boston: Harvard Business School Press, 2006.

ROSEMBLOOM. Canais de Marketing: uma visão gerencial. São Paulo: Atlas, 2002.

SHARMA, A.; MEHROTRA, A. Choosing an Optimal Channel Mix in Multichannel Environments. Industrial Marketing Management, v. 36, n. 1, p. 21-28, 2007.

VINHAS, A. S.; ANDERSON, E. How Potential Conflict Drives Channel Structure: concurrent (direct and indirect) channels. Journal of Marketing Research, v. 42, p. 507-515, 2005 .

WEBB, K. L.; HOGAN, J. E. Hybrid Channel Conflict: causes and effects on channel performance. Journal of Business \& Industrial Marketing, v. 17, n. 5, p. 338-356, 2002. 